\title{
Radioguided Surgery for Breast Cancer - Preliminary Experience in Piaui
}

\author{
Benedita Abreu*, Nayana Melo, Sabas Vieira, Evandro Abreu, João Batista de Abreu and \\ Antonio de Pádua Filho \\ Centro Bionuclear de Diagnóstico; Universidade Estadual do Piauí; Universidade Federal do Piauí; Hospital São \\ Marcos; bionuclear@uol.com.br; Teresina-PI - Brasil
}

\begin{abstract}
Intraoperatory detection and excision of sentinel lymph node (SLN), radioguided occult lesion localization $(R O L L)$ and lesional resection, or a combination of these two procedures at one time in a same patient (SNOLL), are techniques that represent, at the moment, a significant advance in breast cancer surgery, procedures in clinical practice being established, as can be seen from the medical literature, as well as in this institution. Thirtyone patients with breast cancer were initially treated with the aid of radioguided surgery. Of those, 20 patients were submitted to sentinel lymph node biopsy, six have undergone only ROLL and five were submitted to a combination of the two techniques.
\end{abstract}

Key words: Breast cancer, sentinel lymph node, intraoperative probe.

\section{INTRODUCTION}

Breast cancer is one of the most frequent malignant neoplasias in women and, because of its increasingly earlier diagnosis, a correspondingly decreasing number of patients with compromised axillary lymph nodes has been found. Thus, sentinel lymph node biopsy has been proposed as an alternative to complete axillary dissection in patients having small invasive tumors and clinically negative axilla, considering the main advantage of this procedure to be a decrease in the associated morbidity of a large axillary dissection, with its varied clinical aspects of limphoedema, seroma and nervous and/or vascular lesions (Veronesi et al., 1997; Vijayakumar et al., 2005).

Another challenging situation posed to mastologists has been the effective demarcation of those lesions even more precociously detected through ultra-sound and high-resolution mammography, with the aim of performing a better resection of them. This objective has become possible through the extention of the use of the radiopharmaceutical $(99 \mathrm{~m}$ technetiumcolloid) to intra-lesional injection (Mariani et al., 2001). This technique, originally described by Paganelly, Veronesi and coworkers as radioguided occult lesion localization (ROLL) has been used for intra-operatory detection of non-palpable breast lesions with a high degree of suspicion of malignity, permitting a better centering of the lesion with resection of a smaller volume of tissue (Veronesi et al., 1997).

A combination of the two techniques has been used when sentinel node and impalpable lesion localization (SNOLL) is needed for the same patient in a unique operatory procedure. That

\footnotetext{
* Author for correspondence
} 
may be an indication in case of highly suspected lesions, mainly those with higher degrees in BIRADS grading (Barros et al., 2005).

Both selective sentinel lymphadenectomy, for which previous breast lymphocintigraphy for node labeling and finding is necessary, as well as radioguided resection of non-palpable injected lesion, are established as routine procedures in patients fitting certain indication criteria. It may be for determination of nodal status, which may spare total axillary lymphadenectomy in those patients showing a non-compromised studied node, as well as to aid in having an economical but secure resection in case of non-palpable lesions. Another possibility is the joint use of the two techniques, as previously suggested (Cachin et al., 2003). This paper presents the initial experience of the medical team involved in radioguided surgery for breast cancer in Teresina, Piaui.

\section{MATERIAL AND METHODS}

In the present study, 31 patients were submitted to radioguided surgery procedures, between March and June, 2005. Lymphoscintigraphy/node localization and excision alone (SLN) were employed with 20 patients; radiolabeling/radioguided intraoperatory resection of the lesion (ROLL) occurred with six patients; five patients were submitted to both techniques at the same operating time (SNOLL). Average patient's age was about 54,2 (43 - 72).

The administered dosage for pre-operatory lymphoscintigraphy was $300-600 \quad \mu \mathrm{Ci}$ (microcuries) of Dextran-99mTc, injected intradermally at the periareolar region or a deeper peritumoral injection. Visualizing, marking the skin and imaging of the hot sentinel node were performed by gamma camera before surgery. Finding and romoving the node were achieved through a gamma probe aid during the intra-operatory course. Once detected and excised, the frozen examination of the sentinel lymph node was performed at a first moment, and, even if it were to be negative for malignancy, late pathological study with paraffin is also performed for detection of metastasis.

Radionuclide demarcation of non-palpable lesions through the ROLL technique was achieved by intra-tumoral administration of colloidal-labeled 99mTc. Radiocolloid injection was accomplished under ultra-sonography or stereotaxic mammography guidance, depending on which provided better lesion visualization. Pre-operatory images were acquired by a gamma camera and lesion projection was marked on the skin of the breast. Intra-operatory detection of the lesion was performed with a probe and surgical biopsy was carried out.

It is possible to perform lesional excision and biopsy of sentinel lymph node through a combination of the SLN localization by lymphoscintigraphy and intra-lesional injection for marking of the non-palpable lesion (ROLL). This combined technique (SNOLL) can be preferable in cases of lesions in which biopsy was not previously performed, although being highly suspicious, mainly if BIRADS V. Once the lesion has been removed, and if malignancy is confirmed, selective lymphadenectomy of the sentinel node must be performed by the surgeon under gamma probe guidance, using the report of the the frozen study as a standpoint to define if further axillary dissection will or will not be necessary (Barros et al., 2005; Kim et al., 2004).

\section{RESULTS AND DISCUSSION}

In the present study, the SLN identification rate by lymphoscintigraphy was of $92 \%$ (23/25). Two patients who had peritumoral radiopharmaceutical administration did not show successful tracer drainage, and those were patients who had previously been submitted to biopsy or a lesional excision procedure. Lymphoscintigraphy for SLN identification must be carefully evaluated in the case of patients who have had previous neoplasia, undergone previous chemotherapy or excisional biopsy procedures (Mariani et al., 2001; Cachin et al., 2003).

SLN localization was axillary in $84 \%$ (21/25) of the patients, and drainage to internal mammary chain occurred in two cases (8\%). The localization rate between procedures in which the sentinel node was localized and removed was $84 \%$ (21/25). Excised nodes were 28, representing an average of 1,12 per patient. In five patients, sentinel nodes were positive for malignancy $(20 \%)$, and further axillary dissection was followed. Sixteen (16) patients had negative sentinel nodes, as verified both by 
conventional frozen section and paraffin histological studies.

Detection and biopsy of the SLN stands as a valid method for indication of complete axillary dissection in initial breast cancer, and the ROLL technique has gained increasing acceptance in detection of non-palpable breast lesions (De Cicco et al., 2002; Barros et al., 2005). Use of the ROLL technique does not show the serious problems that may occur with the use of the hook-wire, such as bleeding, displacement of the wire and wrong positioning. This novel technique has proved to be feasible and confident for occult lesion localization, in addition to centering of the lesion into the removed specimen (Luini et al., 1999).

In this study, complete removal of lesion was possible in $100 \%$ of the patients submitted to lesional marking with radioactive material. The lesions were free of disease margins, as assured by histopathologic studies or X-rays of surgical specimen. In some cases initial lesions were represented by microcalcification; in $72.7 \%$ $(8 / 11)$, lesion resection was complete in the first tissue specimen. Of 11 ROLL patients, five had positive diagnosis for malignancy as reported from histopathologc studies.

Radionuclide sentinel lymph node (SLN) localization and biopsy is a staging procedure that is used to evaluate patients with invasive breast cancer who have clinically normal axillary nodes. With the ROLL technique, the exact site of the radiolabed lesion can be checked at any time during and at the end of the surgical procedure. The results permit centering of the lesion, usually sparing any further resection area enlargement. The combined technique radioguided sentinel lymph node plus occult lesion localization (SNOLL) — is a choice for accurate localisation of both non-palpable lesions and sentinel node. These procedures may represent an important aid in surgical management of breast cancer, as can be concluded from an analysis of the medical literature.

\section{RESUMO}

A detecção intraoperatória e excisão do linfonodo sentinela (LNS), a localização radioguiada de lesões ocultas (ROLL) e ressecção lesional, ou a combinação desses dois procedimentos ao mesmo tempo em um mesmo paciente (SNOLL), são técnicas que representam, no momento, um significativo avanço na cirurgia do câncer da mama, consistindo em procedimentos firmados na prática clínica, o que se verifica da literatura médica recente e se confirma na experiência inicial deste grupo, aqui relatada. Um total de trinta e uma pacientes com câncer de mama foram submetidas a cirurgia radioguiada. Dessas, 20 foram submetidas apenas a linfadenectomia axilar seletiva do sentinela; 6 pacientes foram submetidas a ressecção intraoperatória radioguiada de lesão não palpável da mama e 5 outras beneficiaram-se da combinação das duas técnicas.

\section{REFERENCES}

Barros, A. C. S. D. and Baros, M. A. C. (2005), Current Surgical Management of Breast Carcinoma Radioguided Diagnosis and Sentinel Lymph Node Biopsy at the Same Surgery. Femina., 33, 269-274.

Cachin, F.; Geissler, B.; Mestas, D.; Bernard, F.; De Freitas, D.; Le Bouedec, G.; Gimbergues, P.; Da Cunha, M.; Kauffman, P.; Gauthier, J. P.; De Latour, M.; Penault-Llorca, F.; Dauplat, J. and Maublant, J. (2003), Peritumoral versus periareolar injection in breast cancer sentinel lymph node detection. The Journal of Nuclear Medicine, abstract book., 25, 126.

De Cicco, C.; Pizzamiglio, M.; Trifirò, G.; Luini, A.; Ferrari, M.; Prisco, G.; Galimberti, V.; Cassano, E.; Viale, G.; Intra, M.; Veronesi, P. and Paganelli, G. (2002), Radioguided occult lesion localisation (ROLL) and surgical biopsy in breast cancer. Technical aspects. Q. J. Nucl. Med., 46, 145-151.

Kim, J.; Chung, D. and Spillane, A. (2004), Combined radioguided occult lesion and sentinel node localization for breast cancer. ANZ J. Surg., 74, 550-553.

Luini, A.; Zurrida, S.; Paganelli G.; Galimbert, V.; Sacchini, V.; Monti, S.; Veronesi, P.; Viale, G. and Veronesi, U. (1999), Comparasion of radioguided excision with wire localization of occult breast lesions. British Journal of Surgery, 86, 522-525.

Mariani, G.; Moresco, L.; Viale, G.; Villa, G.; Bagnasco, M.; Canavese, G.; Buscombe, J.; Strauss W. and Paganelli, G. (2001), Radioguided Sentinel Node Biopsy in Breast Cancer Surgery. Journal of Nuclear Medicine, 42, 1198-1215.

Veronesi, U.; Paganelli, G.; Galimbert, V.; Viale, G.; Zurrida, S.; Bedoni, M.; Costa, A.; De CiCCo, C.; Geraghty, J.G.; Luini, A.; Sacchini, V. and Veronesi, P. (1997), Sentinel-node biopsy to avoid axilary dissection in breast cancer with clinically negative lymph-nodes. The Lancet., 349, 1864-1867. 
Vijayakumar, V.; Boerner, P. S.; Jani, A. B. and Vijayakumar, S. (2005), A critical review of variables affecting the accuracy and false-negative rate of sentinel node biopy procedures in early breast cancer. Nuclear Medicine Communication., 26, 395-405.

Received: July 04, 2005; Revised: July 14, 2005; Accepted: August 01, 2005. 